\title{
Use of assistive technology in cognitive rehabilitation: exploratory studies of the opinions and expectations of healthcare professionals and potential users
}

Citation for published version (APA):

de Joode, E. A., van Boxtel, M. P. J., Verhey, F. R., \& van Heugten, C. M. (2012). Use of assistive technology in cognitive rehabilitation: exploratory studies of the opinions and expectations of healthcare professionals and potential users. Brain Injury, 26(10), 1257-1266. https://doi.org/10.3109/02699052.2012.667590

Document status and date:

Published: 01/09/2012

DOI:

10.3109/02699052.2012.667590

Document Version:

Publisher's PDF, also known as Version of record

Document license:

Taverne

Please check the document version of this publication:

- A submitted manuscript is the version of the article upon submission and before peer-review. There can be important differences between the submitted version and the official published version of record.

People interested in the research are advised to contact the author for the final version of the publication, or visit the DOI to the publisher's website.

- The final author version and the galley proof are versions of the publication after peer review.

- The final published version features the final layout of the paper including the volume, issue and page numbers.

Link to publication

\footnotetext{
General rights rights.

- You may freely distribute the URL identifying the publication in the public portal. please follow below link for the End User Agreement:

www.umlib.nl/taverne-license

Take down policy

If you believe that this document breaches copyright please contact us at:

repository@maastrichtuniversity.nl

providing details and we will investigate your claim.
}

Copyright and moral rights for the publications made accessible in the public portal are retained by the authors and/or other copyright owners and it is a condition of accessing publications that users recognise and abide by the legal requirements associated with these

- Users may download and print one copy of any publication from the public portal for the purpose of private study or research.

- You may not further distribute the material or use it for any profit-making activity or commercial gain

If the publication is distributed under the terms of Article $25 \mathrm{fa}$ of the Dutch Copyright Act, indicated by the "Taverne" license above, 


\title{
Use of assistive technology in cognitive rehabilitation: Exploratory studies of the opinions and expectations of healthcare professionals and potential users
}

\author{
Elisabeth A. de Joode, Martin P. J. van Boxtel, Frans R. Verhey \& Caroline M. \\ van Heugten
}

To cite this article: Elisabeth A. de Joode, Martin P. J. van Boxtel, Frans R. Verhey \& Caroline M. van Heugten (2012) Use of assistive technology in cognitive rehabilitation: Exploratory studies of the opinions and expectations of healthcare professionals and potential users, Brain Injury, 26:10, 1257-1266, DOI: 10.3109/02699052.2012.667590

To link to this article: https://doi.org/10.3109/02699052.2012.667590

\section{曲 Published online: 09 May 2012.}

\section{Submit your article to this journal $\sqsubset$}

Џlll Article views: 1039

Q View related articles $\longleftarrow$

Citing articles: 10 View citing articles 5 


\title{
Use of assistive technology in cognitive rehabilitation: Exploratory studies of the opinions and expectations of healthcare professionals and potential users
}

\author{
ELISABETH A. DE JOODE, MARTIN P. J. VAN BOXTEL, FRANS R. VERHEY, \& \\ CAROLINE M. VAN HEUGTEN
}

Department of Psychiatry and Neuropsychology/School for Mental Health and Neurosciences, Maastricht University, Maastricht, The Netherlands

(Received 4 Fuly 2011; revised 21 December 2011; accepted 9 February 2012)

\begin{abstract}
Objective: To provide recommendations for the successful implementation of Assistive Technology (AT) in cognitive rehabilitation by investigating the attitudes towards AT of professionals, individuals with acquired brain injury (ABI) and their caregivers in two exploratory studies.

Method: A total of 147 professionals in cognitive rehabilitation filled out a web-based survey. Fifteen patients with ABI and 14 caregivers were interviewed.

Results: Most professionals were willing to use AT in the future, although only $27 \%$ used AT currently in a treatment setting. Professionals with AT experience were more positive than those without about the potential of AT and their own ability to use it in their treatment programmes. Most patients and caregivers were positive about using AT in the future, still, only a minority currently used AT. Refusal to reimburse AT devices by health insurance companies appeared an important barrier for a more widespread use.

Conclusions: Although enthusiasm about AT was evident in both studies, a lack of progress in the implementation of AT was noted. This could be improved by promoting knowledge and hands-on experience of professionals who work in rehabilitation centres. More evidence on the efficacy of AT is required to improve coverage of AT devices by insurance companies.
\end{abstract}

Keywords: Brain injury, patients, caregivers, attitude, implementation, diffusion of innovation

\section{Introduction}

The most prevalent types of acquired brain injury (ABI) are stroke and traumatic brain injury (TBI). Stroke can lead to disabilities, problems with participation in society and long-term healthcare dependency $[1,2]$. A wide variety of sequelae are found after brain injury. In particular, its psychological and social consequences may lead to problematic situations in everyday life $[3,4]$. Cognitive deficits are common after stroke [5, 6] and TBI [7]. For example, Rasquin et al. (2002) [6] reported impairments in memory (20\%), processing speed $(50 \%)$ and attention $(46 \%)$ in patients who suffered a stroke. Such deficits can be persistent and may interfere with daily life functioning even years after the brain injury occurred $[5,8]$. Cognitive impairments are not only a heavy burden for patients, but may also lead to strain, distress, depression and a decreased quality-of-life in caregivers. Several studies reported high levels of care burden in partners of patients who suffer from severe physical and cognitive deficits following a stroke $[9,10]$.

Correspondence: C. M. van Heugten, School for Mental Health and Neuroscience, Maastricht University, PO Box 616 , 6200 MD Maastricht, The Netherlands. Tel: +31 43388 4091. Fax: +3143388 4092. E-mail: c.vanheugten@maastrichtuniversity.nl 
It is often necessary to adopt compensatory strategies to overcome acquired cognitive impairments after ABI. Several studies have suggested that the use of Assistive Technology (AT) as a cognitive aid to support prospective memory and planning could be beneficial for the daily life functioning of individuals with ABI. Intervention studies have reported improvements in self-ratings of performance on everyday life tasks [11] and enhancement of independent behaviour in daily life through the use of AT [12, 13] in children, adolescents and adults with ABI.

Other applications of AT have been described in previous studies. Kirsch et al. [14] studied the use of a customized PDA in patients with TBI as a conversational aid to decrease verbose speech. AT to assist speech and language is commonly known as augmentative and alternative communication (AAC). It is used increasingly by both children and adults, as well as in different patient groups such as patients with cerebral palsy, amyotrophic lateral sclerosis (ALS), aphasia and apraxia of speech and dementia [15-18].

Another application for AT is assisting users in route finding, which has been described in several patient groups, such as TBI [19], ABI [20] and cognitive deficits due to intellectual disability, dementia and schizophrenia [21].

However, the use of AT is not yet widespread and strategies need to be developed to stimulate the application of AT to support individuals with cognitive deficits. Especially in cognitive rehabilitation, where patients try to regain or maintain their independence through the use of cognitive aids, AT could be a useful addition to the therapeutic interventions. To this end, it is necessary to investigate the opinions and expectations about AT of all major stakeholders.

More specifically, these stakeholders are the potential users, i.e. patients with ABI, their primary caregivers (who are often involved in the use of cognitive aids as well) and the rehabilitation professionals, who tend to introduce AT to potential users and assist them in the daily use of such devices.

To date, only two papers have described the expectations and opinions of professionals working in cognitive rehabilitation regarding the use of AT as a cognitive aid $[22,23]$. Both papers used data from a survey involving 81 professionals from four rehabilitation centres and visitors of a workshop about the use of AT in TBI care. These professionals recognized the potential of AT in cognitive rehabilitation, although they felt limited by the costs of AT devices and by a lack of confidence in their own ability to support patients in the use of such devices. Furthermore, professionals who used AT in their own daily life (i.e. not as an aid for patients with $\mathrm{ABI}$ ) were significantly more confident about their own ability to assist patients in the use of AT than those who did not use AT at all. Still, only $36 \%$ of the respondents had ever used AT in a professional setting and even less respondents $(17 \%)$ used AT themselves [13].

The opinions of potential users of AT, such as personal digital assistants (PDAs) or pagers, was described in a study by Hart et al. [24] in 2004. The researchers interviewed 80 adults with moderateto-severe TBI who were recruited from several outpatient and residential treatment programmes. Less than one third had experience with AT. However, although they were satisfied with their current strategies for memory and organizational tasks, they were very interested in using such devices in the future. Respondents showed a high level of consensus about desirable device features, such as user friendliness, as well as about preferred functions such as remembering 'to-do' tasks. The authors concluded that AT was acceptable and desirable for this patient group.

The above-mentioned studies on this topic are at least 5-years old. As this kind of technology is more common and accepted today and the possibilities are evolving rapidly, the authors expected to find that professionals and potential users today may have an altered, more positive outlook on the use of AT in cognitive rehabilitation. Furthermore, in contrast with the previous studies, the present study included not only individuals with TBI as potential users, but also those who suffered a stroke. Moreover, the opinions of all major stakeholders, viz., professionals, patients and caregivers, were compiled in order to obtain a more complete picture of today's views on the use of AT and to identify the important pre-requisites for an implementation strategy for AT in cognitive rehabilitation.

A successful implementation of AT in clinical practice requires consideration of the expectations and opinions of all major parties involved (the 'stakeholders') [25]. This includes assessing the level of support among stakeholders for AT and their knowledge, wishes and expectations. More specifically, this study set out to assess reasons to use PDAs because of a current ongoing randomized clinical trial into the efficacy of a PDA as a cognitive aid. Furthermore, limiting and facilitating factors were identified that could affect successful implementation. Taking into account the aims and interests of stakeholders is important for AT to be successfully integrated in clinical practice. Additionally, the authors were interested in the current use of AT, when it is used and which considerations play a role in the decision to use AT instead of a more traditional aid [25]. It was expected to find that previous experience 
(personal or professional) would be associated with a more positive attitude towards AT.

Study I will describe the opinions and expectations towards AT of professionals and study II will describe those of patients with ABI and their caregivers. The main questions in both exploratory studies were: to what extent do the stakeholders use AT in cognitive rehabilitation and which factors are related with the use of AT and the attitude towards AT in individuals with brain injury.

\section{Method}

The first group of stakeholders were professionals working in cognitive rehabilitation (study I). The second group of stakeholders included in this study consisted of potential users of AT, i.e. individuals with $\mathrm{ABI}$ and their caregivers (study II). The two groups of stakeholders will be presented separately in this paper. Both studies were performed in the Netherlands.

\section{Study I: Survey among professionals}

In September 2009 an email with a link to a webbased questionnaire was sent to 328 participants in a symposium on stroke-related cognitive rehabilitation. In total, 147 (45\%) questionnaires were filled out by this convenience sample over a 4 -week period. The survey was developed based on earlier research and a consensus meeting of the authors. It consisted of 20 questions (multiple choice with space for open comments), which took $\sim 15$ minutes to fill out. Themes covered in this survey were demographic variables (age, sex and educational level), professional background and work experience. Other questions related to personal and professional experience with $\mathrm{AT}$ and opinions and expectations on the use of AT by patients in cognitive rehabilitation. Finally, important considerations with respect to and contraindications for the use of AT were assessed. A copy of the survey can be obtained from the corresponding author. No further information on non-responder characteristics was available.

\section{Study II: Interviews with potential users}

Between March 2008 and October 2009 rehabilitation psychologists and physicians from rehabilitation centres (who also took part in an ongoing randomized clinical trial into the efficacy of a PDA as a cognitive aid) referred patients to the researcher for a semi-structured interview. All patients were discharged from rehabilitation and were in the chronic phase of brain injury. Due to cognitive difficulties in this study population, filling out a survey could lead to missing items or comprehension difficulties.
Therefore, the interview consisted of open questions, which enabled the collection of more in-depth and complete information. The current method made it possible to rephrase questions for better understanding if needed and the interviewer could ask follow-up questions to get a complete answer to the questions. If, for example, a patient did not mention the presence of a common cognitive complaint, the interviewer could ask specifically about that complaint. Also, the caregiver could verify the information provided by the patient, when necessary.

Interviews were conducted at the rehabilitation centre or at the patients' home. Patients and their caregivers were interviewed separately and each interview took $\sim 40$ minutes to complete. The questions related to demographics (age, sex and level of education), type of brain injury and cognitive complaints. Other questions related to current use of cognitive aids, experience with AT and reasons for use, suitability for patients and the confidence of caregivers in supporting them (a copy of the interview is available from the corresponding author). After each interview it was determined whether new, additional information had been obtained. Data collection in additional participants continued until the authors judged that saturation had been reached (i.e. no new information on the attitude towards AT use was obtained). This saturation point was reached after interviewing a total of 15 patients and 14 caregivers. The local medical ethics review board approved of the study and all participants gave their informed consent.

\section{Statistical analyses}

In both studies the statements about the use of AT were answered on a 5-point scale (1: disagree, 2: slightly disagree, 3: no opinion/neutral, 4: slightly agree, 5: agree). Educational level was measured on an 8-point scale, ranging from 1 (elementary school) to 8 (university degree) [26]. Other demographic variables were age and sex. Descriptive statistics of participant characteristics were calculated. Statistical analyses were performed with PASW statistical software (version 18.0.2 for Apple Macintosh), with an alpha level set at 0.05 for all analyses.

\section{Statistical analyses study I: Survey among professionals}

In addition to the factors age, educational level and sex, also the number of years of professional experience was documented, as it was expected to find that previous experience with AT would affect the attitudes about the use of AT. Chi-square tests and Mann-Whitney tests were used to compare the opinions and expectations of professionals with and without prior experience with AT. 
A regression analysis was performed to determine the factors that could predict a positive attitude towards the use of AT. In the first block of predictors, demographic variables (age, sex, educational level and years of work experience) and personal use of AT were entered. In the second block, previous professional experience with AT was entered. The outcome variable 'Attitude towards AT' was a compound score, based on eight statements (see the Appendix for the items used in the compound score). The validity of this compound score was tested in a factor analysis with a direct oblimin (oblique) rotation on data gathered from 139 participants. Two statements showed a lack of correlation with the other six statements and were excluded. One component was extracted with acceptable reliability (Cronbachs $\alpha=0.70$ ), indicating that these statements were part of one construct, labelled as 'attitude towards AT'.

\section{Statistical analyses study II: Interviews with potential users}

This study did not perform a regression analysis on the sample of potential users, as the sample was considered to be too small. Thus, the data from the potential user interviews were only used descriptively.

\section{Results}

\section{Study I: Survey among professionals}

The sample of 147 professionals consisted of occupational therapists $(25.2 \%)$, physical therapists $(28.6 \%)$, rehabilitation or geriatric physicians $(17.7 \%)$, nurses $(5.4 \%)$, rehabilitation psychologists $(4.8 \%)$ or other professionals in cognitive rehabilitation (18.3\%) (see Table I for more demographic characteristics). The number of years of professional experience ranged from 1-37 years, with a median of 6 years.

Almost all of the professionals had treated patients who had suffered a stroke $(96 \%)$ and most had treated patients with traumatic brain injury (TBI)

Table I. Professionals' characteristics: means (standard deviations) or percentages.

\begin{tabular}{lc}
\hline & $\begin{array}{c}\text { Professionals } \\
(n=147)\end{array}$ \\
\hline Sex $(\%$ men $)$ & $17.7 \%$ \\
Age in years & $38.3(10.3)$ \\
Educational level & $6.5(0.9)$ \\
\hline
\end{tabular}

Only participants with an educational level of 6 (bachelor degree) or higher were present in this group.
$(64 \%)$ or patients with brain damage due to cancer or radiation treatment for cancer $(51 \%)$. Almost one-third $(29 \%)$ reported having treated other patient groups, such as patients with multiple sclerosis, chronic pain or dementia. The most common types of cognitive problems they encountered were related to attention $(84 \%)$, memory $(80 \%)$, executive function $(75 \%)$ and neglect $(80 \%)$. Other treated cognitive problems were apraxia (67\%), speed of information processing $(65 \%)$ and aphasia (42\%).

When asked to describe their experience with AT for personal use, almost half of all professionals reported personal experience with the use of a digital calendar $(41.5 \%)$ in their own daily life. Of these users, most used a calendar on their personal computer $(72 \%)$, while others chose a cell phone $(57 \%)$ or a PDA $(31 \%)$ with a calendar function. Only a small minority (5\%) reported negative experiences with these devices.

Use of AT in a treatment setting. Professionals were asked to report their use of AT in a treatment setting, the frequency of use and whether the patient or they themselves had initiated the use of AT. A minority of the respondents reported previous experience with AT in a treatment setting $(27.9 \%)$. Professionals with AT experience did not differ significantly from professionals without AT experience on demographic variables such as age, years of professional experience or sex, but AT experience was more common in the higher educated group $\left(\chi^{2}=4.55\right.$, $\mathrm{df}=1, p=0.033)$.

According to the professionals, the initiative to use AT came more often from the professional than from the patient. When asked how many times in the last 2 years they had used different kinds of AT as a cognitive aid, professionals reported the use of PDAs $(43.9 \%)$ and cell phones with calendar function $(53.7 \%)$, as initiated by professionals. Reported applications of AT initiated by patients were PDAs (29.3\%) and cell phones (34.1\%).

When asked if AT should be standard care in rehabilitation treatment, all respondents were moderately positive (Table II). With the statement that AT is part of modern life and should therefore also be part of rehabilitation treatment, most respondents agreed, although professionals with experience in a treatment setting were more positive than those without experience $(\mathrm{U}=1574, p=0.006)$. Most respondents also agreed with the statement 'AT improves the independence of patients'. However, professionals with experience were again more positive than those without experience $(\mathrm{U}=1407$, $p=0.001)$. Different opinions were reported with regard to the statement 'I have positive experiences 
with $\mathrm{AT}^{\prime}$ (4.27 vs 2.84); as expected, experienced professionals were more often in agreement with this statement than professionals without experience $(\mathrm{U}=601.5, p<0.001)$. The final statement 'AT offers much more options than pen-and-paper cognitive aids' received neutral-to-positive opinions from all of the professionals.

Considerations on the future use of AT. Professionals with experience all wanted to use AT more in the future and almost all professionals without any experience in the use of AT in rehabilitation treatment were willing to use AT in the future (Table III). Only nine respondents answered negatively, reasons for this were 'It isn't relevant in the acute phase' (4), 'It is not my area of expertise' (3) or 'No added value/not effective' (2).

Table II. Scores of professionals on statements ${ }^{a}$ about attitude towards AT (means and standard deviations).

\begin{tabular}{|c|c|c|}
\hline & $\begin{array}{l}\text { Professionals } \\
\text { with AT } \\
\text { experience } \\
(n=41)\end{array}$ & $\begin{array}{c}\text { Professionals } \\
\text { without AT } \\
\text { experience } \\
(n=106)\end{array}$ \\
\hline $\begin{array}{l}\text { AT should be standard care in } \\
\text { cognitive rehabilitation }\end{array}$ & $3.27(1.40)$ & $3.28(1.19)$ \\
\hline $\begin{array}{l}\text { AT is part of modern life and } \\
\text { should therefore also be } \\
\text { included in cognitive } \\
\text { rehabilitation }\end{array}$ & $4.41(0.84)$ & $3.97(0.98)^{\star}$ \\
\hline $\begin{array}{l}\text { AT improves the indepen- } \\
\text { dence of patients }\end{array}$ & $4.22(0.70)$ & $3.75(0.73)^{\star}$ \\
\hline $\begin{array}{l}\text { I have positive experiences } \\
\text { with AT }\end{array}$ & $4.27(0.78)$ & $2.84(1.01)^{\star}$ \\
\hline $\begin{array}{l}\text { AT offers much more options } \\
\text { than pen-and-paper } \\
\text { cognitive aids }\end{array}$ & $3.71(0.81)$ & $3.52(0.84)$ \\
\hline
\end{tabular}

${ }^{a}$ Likert scale (1 (disagree)-5 (agree)); ${ }^{\star}$ Mann-Whitney test: $p<0.05$; AT, Assistive Technology.

Table III. Reasons not to use AT reported by professionals.

\begin{tabular}{lcc}
\hline & $\begin{array}{c}\text { Professionals } \\
\text { with AT } \\
\text { experience } \\
(n=41)\end{array}$ & $\begin{array}{c}\text { Professionals } \\
\text { without AT } \\
\text { experience } \\
(n=106)\end{array}$ \\
\hline It is unknown/I lack knowledge & $22.0 \%$ & $47.2 \%$ \\
$\begin{array}{l}\text { I don't have any experience } \\
\quad \text { with it }\end{array}$ & $0.0 \%$ & $35.8 \%$ \\
$\begin{array}{l}\text { It's too expensive } \\
\text { Lack of (IT) support in the } \\
\quad \text { workplace }\end{array}$ & $58.5 \%$ & $48.1 \%$ \\
$\begin{array}{l}\text { The time investment is too } \\
\text { large }\end{array}$ & $7.3 \%$ & $17.0 \%$ \\
\hline
\end{tabular}

The fact that these devices are not yet covered by health insurance was a main reason not to use them in cognitive rehabilitation by half of the professionals, while lack of (IT) support in the workplace and the time investment needed for professionals to learn how to use AT proved less important obstacles (Table III). No significant differences between AT-experienced and AT-inexperienced professionals were found on these variables. However, two other reasons not to use AT were reported more often by AT-inexperienced professionals, namely lack of knowledge of this kind of technology $\left(\chi^{2}=7.83, \mathrm{df}=1, p=0.005\right)$ and lack of experience with $\operatorname{AT}\left(\chi^{2}=19.82, \mathrm{df}=1, p<0.001\right)$.

Opinions about the use of a PDA as a cognitive aid. Professionals were also presented with a number of statements in order to determine the potential applicability of PDAs as cognitive aids (see Table IV).

Most respondents agreed with the statement 'PDAs can be successfully used in cognitive rehabilitation'. When professionals without AT experience were compared to professionals with AT experience, the first group was less positive about the potential success of AT $(U=1556, p=0.018)$. Technical knowledge was not considered essential and most professionals felt confident that they would be able (after instruction) to assist patients with the use of a PDA, although again inexperienced professionals were less positive $(\mathrm{U}=1451.5, p=0.003)$. Another consideration, namely the time investment needed by patients to learn to use a PDA, was not an obstacle according to most respondents.

Table IV. Statements ${ }^{a}$ by professionals about reasons to use PDAs (means and standard deviations).

\begin{tabular}{lcc}
\hline & $\begin{array}{c}\text { Professionals } \\
\text { with AT } \\
\text { experience } \\
(n=41)\end{array}$ & $\begin{array}{c}\text { Professionals } \\
\text { without AT } \\
\text { experience } \\
(n=106)\end{array}$ \\
\hline $\begin{array}{l}\text { PDAs can be used successfully } \\
\text { in cognitive rehabilitation }\end{array}$ & $4.08(0.94)^{\star}$ & $3.77(0.74)^{\star}$ \\
$\begin{array}{l}\text { Technical computer knowl- } \\
\text { edge is essential for proper } \\
\text { use of a PDA }\end{array}$ & $2.63(1.08)$ & $2.70(1.03)$ \\
$\begin{array}{l}\text { It takes too long for patients to } \\
\text { learn to use a PDA }\end{array}$ & $1.98(0.85)$ & $2.21(0.92)$ \\
$\begin{array}{l}\text { I am confident that I am able } \\
\text { to (help the patient to) work } \\
\text { with a PDA }\end{array}$ & $4.35(0.86)^{\star}$ & $3.88(0.89)^{\star}$ \\
$\begin{array}{l}\text { I need help with teaching my } \\
\text { patients how to use a PDA }\end{array}$ & $3.63(1.19)$ & $3.53(1.15)$ \\
\hline $\begin{array}{l}{ }^{a} \text { Likert scale (range 1 (disagree)-5 (agree); } \\
\text { Digital Assistant; }{ }^{\star} \text { Mann-Whitney test: } p<0.05 .\end{array}$
\end{tabular}


Attitude towards the use of AT. Data from the current study presented so far already showed that previous professional experience with AT is related to the attitude of professionals towards AT in cognitive rehabilitation. This was confirmed by the results of the regression analysis. Previous professional experience with AT was the only significant contributor to the regression model, with the other variables (age, sex, educational level, years of work experience and personal use of assistive technology) also included in the regression model $(b=0.309$, $t(146)=3.44, p<0.001)$. When the model including previous professional experience with AT was compared with the model without professional experience, the difference between the models was significant, $\quad \Delta R^{2}=0.077, \quad \Delta F(1,144)=11.83$, $p<0.001$.

\section{Study II: Interviews with potential users}

In total 15 patients and 14 caregivers were interviewed. Two patients did not have a caregiver who was willing to participate. One patient was not able to participate, but his caregiver was. The patient group consisted of 11 men and four women. All patients had acquired brain injury as an adult at least 9 months before the interview took place. Six individuals had suffered TBI $(40 \%)$, six experienced a stroke $(27 \%)$ and three had other causes of brain injury, namely subarachnoid haemorrhage $(n=2)$ and cerebral damage due to hypoxia during a status epilepticus $(n=1)$. They all lived at home and all but one had experienced a change in their occupational ability. Patients were not professionally active anymore $(73 \%)$ or worked less $(20 \%)$ due to their brain injury. They had cognitive complaints concerning memory $(93 \%)$, attention $(93 \%)$, information processing $(80 \%)$, planning $(73 \%)$ or initiative/perseveration $(73 \%)$. They all used non-electronic cognitive aids such as calendars (73\%), notebooks $(60 \%)$ or other aids, such as pencil-and-paper shopping lists or to-do lists (73\%).

The caregiver group consisted of three men and 11 women, almost all were partners of the patient, one caregiver was the patient's daughter. Other demographic characteristics are shown in Table V.

When potential users were asked about their current use of computers and other AT, it became clear that, while all patients and caregivers used personal computers, only two patients and three caregivers used PDAs: one patient used a PDA as a calendar and four patients used cell phones as cognitive aids.

Eleven patients and 11 caregivers were willing to use AT in the future and, although many reasons for use were reported, most potential users also reported
Table V. Patients' and caregivers' characteristics: means (standard deviations) or percentages.

\begin{tabular}{|c|c|c|}
\hline & $\begin{array}{c}\text { Patients } \\
\text { with ABI } \\
(n=15)\end{array}$ & $\begin{array}{c}\text { Caregivers } \\
(n=14)\end{array}$ \\
\hline Sex (\% men $)$ & $73.3 \%$ & $21.4 \%$ \\
\hline Age in years & $53.5(12.0)$ & $47.1(12.4)$ \\
\hline $\begin{array}{l}\text { Time since brain injury in } \\
\text { months (range) }\end{array}$ & $69.3(9-340)$ & - \\
\hline Educational level & $4.4(2.5)$ & $4.7(1.2)$ \\
\hline
\end{tabular}

ABI, Acquired Brain Injury.

Table VI. Reasons in favour of or against the use of AT reported by potential users.

\begin{tabular}{lcr}
\hline & $\begin{array}{c}\text { Patients } \\
\text { with ABI } \\
(n=15)\end{array}$ & $\begin{array}{c}\text { Caregivers } \\
(n=14)\end{array}$ \\
\hline In favour & & \\
It's easy to take with you & $33 \%$ & $36 \%$ \\
It has multiple functions in one device & $47 \%$ & $43 \%$ \\
It gives a warning prior to a task & $7 \%$ & $7 \%$ \\
Against & & \\
It is unknown/I lack knowledge & $20 \%$ & $21 \%$ \\
I don't have any experience with it & $20 \%$ & $0 \%$ \\
It's too expensive & $20 \%$ & $7 \%$ \\
Another cognitive aid is sufficient & $20 \%$ & $29 \%$ \\
It's unsuitable for myself/the patient & $7 \%$ & $36 \%$ \\
\hline
\end{tabular}

potential obstacles. Both patients and caregivers agreed with the fact that AT typically is portable and that all functions are present in one device are important reasons for use (Table VI). There was less agreement between caregivers and patients about the suitability of AT and about the financial barrier to use AT. More patients than caregivers considered the costs of AT a barrier for use (five patients vs one caregiver) and more caregivers than patients considered AT unsuitable for the patient in question (one patient vs five caregivers).

Opinions about the use of a PDA as a cognitive aid. The respondents were also presented with a number of statements in order to determine the potential applicability of PDAs as cognitive aids (Table VII).

Most respondents agreed with the statement 'PDAs can be successfully used in cognitive rehabilitation'. Technical knowledge was not considered essential and, in agreement with this, most patients were confident about their own ability to use a PDA after instruction. Also, most caregivers felt able to assist patients in using the device or they felt that the 
Table VII. Statements ${ }^{a}$ by patients and caregivers about reasons to use PDAs (means and standard deviations).

\begin{tabular}{lcc}
\hline & $\begin{array}{c}\text { Patients } \\
\text { with ABI } \\
\left(n=14^{b}\right)\end{array}$ & $\begin{array}{c}\text { Caregivers } \\
(n=14)\end{array}$ \\
\hline $\begin{array}{l}\text { PDAs can be used successfully } \\
\text { in cognitive rehabilitation }\end{array}$ & $4.29(0.83)$ & $4.29(0.91)$ \\
$\begin{array}{l}\text { Technical computer knowl- } \\
\text { edge is essential for proper } \\
\text { use of a PDA }\end{array}$ & $2.64(1.28)$ & $2.86(0.86)$ \\
$\begin{array}{l}\text { It takes too long for patients to } \\
\text { learn to use a PDA }\end{array}$ & $1.71(0.99)$ & $2.43(1.02)$ \\
$\begin{array}{l}\text { I am confident that I am able } \\
\text { to (help the patient to) work } \\
\text { with a PDA }\end{array}$ & $4.29(1.20)$ & $3.93(1.27)$ \\
\hline
\end{tabular}

${ }^{a}$ Likert scale (range $\left.1-5\right) ;{ }^{b}$ One patient did not participate due to fatigue.

patients themselves or another caregiver was better equipped to help. Another consideration, namely the time investment needed by patients to learn to use a PDA, was not considered as an obstacle according to most potential users.

\section{Discussion}

This study investigated the opinions and expectations of major stakeholders about the use of AT in cognitive rehabilitation because it was expected that these factors may influence the implementation of AT in everyday life [13]. The opinions and expectations of two groups of stakeholders were explored: professionals in cognitive rehabilitation and potential users, i.e. patients with $\mathrm{ABI}$ and their caregivers. Overall both groups of stakeholders were positive about AT use, but implementation in clinical practice and everyday life is still not widespread.

Two types of information were gathered in the current study to help to identify important prerequisites for the successful implementation strategy of AT in cognitive rehabilitation. First, the chance of successful implementation was assessed, by determining the level of support for a new intervention (i.e. use of AT) and the suitability of the new intervention for the stakeholders. Second, factors that influence the implementation were taken into account; namely, the use of current interventions, the aims and interests of the stakeholders and factors limiting or facilitating implementation. Finally, this study tried to identify sub-groups of stakeholders, in order to be able to adjust the implementation strategy to differences in experience with AT or attitude.

\section{Level of support}

Although a minority of the stakeholders in the current study used AT, almost all of the professionals and about three-quarters of potential users were willing to use AT in the future.

The use of AT is now more common in daily life compared to a few years ago. Therefore, the authors expected to find an increase in the use of AT in both groups compared with earlier research reports. Although comparisons between these studies should be made with caution due to differences in size and composition of the samples, personal use of portable AT by professionals did indeed differ from an earlier study by Hart et al. [22]: $17 \%$ of the professionals used AT in 2003 vs 30\% in this study. In the earlier study, previous AT experience was related to a higher level of clinician confidence [22]. This study showed that previous AT experience was also related to a more positive overall attitude towards AT as a cognitive aid.

Personal use of AT in the patient group was only slightly higher in the current study compared to an earlier study [24] (28\% in 2004 vs $33.3 \%$ in 2009 ). Comparable figures were observed in professional use in a treatment setting compared with a study from 2004 by O'Neil-Pirozzi et al. [23] (36\% in 2004 vs $38 \%$ in 2009 ).

In sum, it seems that, while over the last few years professionals have followed the general trend of increased use of AT in their own daily life, the process of implementation of AT in clinical practice has been delayed or even stalled.

Considering the percentage of current users of AT in cognitive rehabilitation and following the Diffusion of Innovation theory by Rogers [27], several general inferences can be made. In the current field today, the so-called 'innovators' and 'early adopters' are using AT already, as they are attracted by innovation and appreciate the new technology and its features and design. The 'early majority' is now starting to use AT: this sceptical user values efficacy and usability of the intervention above other things. Therefore, implementation strategies for this group of users should focus on improving knowledge about the usability and effectiveness of AT in cognitive rehabilitation.

The 'late majority' are users who start to use new technology because they are afraid to be left behind. They value user experience and reassurance and would benefit from hands-on experience with AT under supervision from an experienced user. Both the early and late majority will have to be targeted in new, yet to be developed, implementation strategies and should be approached in ways that suit their needs. 
Suitability of assistive technology in cognitive rehabilitation

The slow-moving implementation process of AT in cognitive rehabilitation might also be explained in part by the fact that these devices are not yet covered by health insurance in the Netherlands. Both professionals and potential users considered this an important obstacle. Particularly in the Dutch healthcare system, in which most medical interventions are covered by insurance, AT is considered a substantial personal investment. Therefore, higher demands might be made by potential users as well as by professionals on such an 'expensive' aid compared to regular 'free' interventions.

In the current studies the overall attitude of stakeholders towards the suitability of AT in cognitive rehabilitation was positive, although a third of the caregivers felt that AT was unsuitable for their family members with brain injury. AT was viewed as part of modern life and a more widespread implementation of AT in standard care was welcomed. Furthermore, the independence of patients was expected to be improved by the use of AT. Lack of technical knowledge or the time it might take someone to learn to use such an aid were not considered to be important obstacles.

\section{Limiting and facilitating factors in the use of assistive technology}

Several factors could limit or facilitate the implementation of AT and the aims and interests of the stakeholders should be taken into account in developing new implementation strategies. Besides reporting a willingness to use AT more in the future, most professionals in this study felt confident that they were able to assist patients in the use of AT. They did not consider the time investment for patients to be too substantial and most professionals viewed AT as more versatile than pencil-and-paper based aids. Although these results indicate the presence of motivation for a change in treatment routine and therefore facilitate implementation of a new intervention such as AT, it must be kept in mind that current routines are often hard to break [13]. Also, especially professionals without AT experience would benefit from more knowledge of and experience with AT, which in turn could lead to more confidence in their own ability to work with $\mathrm{AT}$ and a more positive attitude to AT in cognitive rehabilitation.

For patients with $\mathrm{ABI}$ and their caregivers similar factors played a role: although they felt confident in their ability to use AT, a lack of knowledge and experience limited the actual use of AT. Also, motivation for change was not always present when another aid sufficiently compensated memory or planning deficits.

\section{Implementation strategies}

Based on the combined information from the current and previous studies some recommendations for implementation strategies can be made. The attitude of professionals towards AT was influenced by experience with AT. Because a positive attitude towards a new therapeutic intervention is important for a change in professional practice [13] and considering the needs of both the early and late majority users, implementation should start with improving knowledge about and experience with AT. Peer meetings under expert supervision could be organized to get professionals acquainted with the application of AT in treatment settings and to provide some hands-on experience [27]. Also, the use of feedback from patients and their caregiver about the use of AT could improve the use in rehabilitation treatment.

To facilitate potential users in making an informed choice about their desired cognitive aid, it is important to improve their level of knowledge and experience as well. AT could be discussed with the patient and caregiver as an alternative for more traditional cognitive aids. Also, the option for patients to try AT while still being in cognitive rehabilitation treatment will allow them to use AT without a need to invest financial resources before they are confident that AT really suits their needs.

Considering the fact that the financial hurdle seems to be one of the largest obstacles to the use of AT, convincing health insurance companies of the efficacy of such aids is important. If the use of AT is covered by health insurance or other funds, its implementation in standard rehabilitation care would be greatly supported.

\section{Strengths and limitations of the current study}

The large and varied sample of professionals who filled out the survey makes generalization of the results possible. There is no reason to assume that the non-responders were less experienced with or interested in AT, although some bias cannot be excluded. In spite of the fact that the sample of potential users was small, the interview technique that was used enabled the gathering of in-depth and verifiable data. However, even though the interviews were performed until no new information was obtained, other additional participants might still have added information and thereby could have enriched the dataset. The current sample might be biased to some extent. Participants might have more interest in this kind of technology than other patients and caregivers and therefore be more positive or 
experienced than the population they represent. However, rehabilitation centres were explicitly informed that eligibility of potential participants for the study was not dependent on expressed interest in or experience with AT. Furthermore, this sample included both patients with stroke as well as TBI, thereby providing a more heterogeneous sample than those used in earlier studies.

One of the strengths of the current study is the compilation of opinions of the two major groups of stakeholders. However, it was difficult to directly compare specific answers because of differences in sample size and query methods used.

In the current study, organizational and financial factors were not taken into account. Therefore, information on the knowledge of and experience with AT in an organization and about the ability of organizations to implement new interventions due to financial or organizational reasons was not included in this study.

The use of technology is not likely to be different in the Netherlands, as compared to other countries in the western world. Still, the healthcare system is based on almost complete coverage of medical aids, while in many other countries this is not the case, therefore it might limit the generalizability of these findings.

When this study was conceived, PDAs were devices with large potential. Due to the fast pace of technological development, smartphones have now largely overtaken pocket PCs on the market and less people are using PDAs. Still, the conclusions about the applicability of PDAs can be generalized to smartphones and the integration of different functions (calendar as well as phone) and applications might even improve the use and implementation in rehabilitation treatment.

\section{Future research}

The implementation of new interventions in clinical practice is a complicated and time-consuming process. The stakeholders not included in this study, more specifically policy-makers in healthcare, and financial parties such as health insurance companies, could provide additional information about the requirements necessary for the successful implementation of AT. It is therefore important that these stakeholders are also involved in future strategies towards a more widespread implementation of AT in cognitive rehabilitation. Their input could be very useful in the investigation of the cost-efficiency of AT vs conventional aids.

Moreover, evidence-based applications of AT in clinical practice could promote the acceptance of such interventions by the stakeholders, as pointed out in a recent review [28]. Hence, the efficacy of dedicated AT should be studied further in randomized controlled trials. These trials could also reveal underlying factors that determine successful use and in turn contribute to a better matching of patient needs and AT.

\section{Conclusion}

This is the first study to investigate the expectations and opinions of both professionals and potential users with regard to the use and implementation of AT. The aim was not only to assess the current state of AT use in cognitive rehabilitation, but also to make recommendations towards improving the implementation of AT in the future.

The present study clearly identified a lack of progress in the implementation of AT in cognitive rehabilitation since the last study conducted on this topic in 2003. This may be due to a wide variety of factors, including financial constraints and lack of knowledge of and experience with AT. Still, all participants in this study demonstrated an overall positive attitude towards AT. In the authors' view 'the innovators' and 'the early adopters' who are already using AT in cognitive rehabilitation are the key to success in future implementation strategies. Strategies that enable professionals to share AT experience with their peers are likely to be most successful in convincing professionals not already using AT to discover its benefits and to share their insights with patients and caregivers. The use of the Internet could enhance the interaction between users as well as professionals, for instance in user groups. Hence, implementation strategies should focus on promoting knowledge and experience within rehabilitation centres in order to improve the acceptance and use of AT in cognitive rehabilitation by all stakeholders.

\section{Acknowledgements}

We would sincerely like to thank the Dutch Network for Cardiovascular Research for their assistance in distributing the survey.

Declaration of Interest: This work was funded by The Netherlands Organization for Health Research and Development (ZonMW, project number 14350052).

\section{References}

1. Khaw KT. Epidemiology of stroke. Journal of Neurology, Neurosurgery and Psychiatry 1996;61:333-338.

2. Scholte Op Reimer W. Long term care after stroke. Studies on care utilisation, quality of care and burden of caregiving. Dissertation, University of Amsterdam; 1999. 
3. van Heugten C, Fasotti L. Revalidatie van cognitieve, emotionele en gedragsmatige gevolgen na verworven hersenletsel. Handboek Handicap en chronische ziekte. Amsterdam: Elsevier; 2004; aanvulling 87:37-56.

4. Sundet K, Finset A, Reinvang I. Neuropsychological predictors in stroke rehabilitation. Journal of Clinical and Experimental Neuropsychology 1988;10:363-379.

5. Hochstenbach JB, den Otter R, Mulder TW. Cognitive recovery after stroke: A 2-year follow-up. Archives of Physical Medicine and Rehabilitation 2003;84:1499-1504.

6. Rasquin SM, Verhey FR, Lousberg R, Winkens I, Lodder J. Vascular cognitive disorders: Memory, mental speed and cognitive flexibility after stroke. Journal of Neurological Sciences 2002;203-204:115-119.

7. van der Naalt $J$, van Zomeren AH, Sluiter WJ, Minderhoud JM. One year outcome in mild to moderate head injury: The predictive value of acute injury characteristics related to complaints and return to work. Journal of Neurology, Neurosurgery and Psychiatry 1999;66: 207-213.

8. Patel M, Coshall C, Rudd AG, Wolfe CD. Natural history of cognitive impairment after stroke and factors associated with its recovery. Clinical Rehabilitation 2003;17:158-166.

9. Scholte op Reimer W, de Haan R, Rijnders P, Limburg M. The burden of caregiving in partners of long-term stroke survivors. Stroke 1998;29:6.

10. Visser-Meily A, van Heugten C, Post M, Schepers V, Lindeman E. Intervention studies for caregivers of stroke survivors: A critical review. Patient Education and Counseling 2005;56:257-267.

11. Gentry TAP, Wallace J, Kvarfordt C, Lynch KB. Personal digital assistants as cognitive aids for individuals with severe traumatic brain injury: A community-based trial. Brain Injury 2008;22:19-24.

12. Depompei R, Gillette Y, Goetz E, Xenopoulos-Oddsson A, Bryen D, Dowds M. Practical applications for use of PDAs and smartphones with children and adolescents who have traumatic brain injury. NeuroRehabilitation 2008;23: 487-499.

13. Wilson BA, Emslie H, Quirk K, Evans J, Watson P. A randomized control trial to evaluate a paging system for people with traumatic brain injury. Brain Injury 2005;19: 891-894.

14. Kirsch N, Shenton M, Spirl E, Simpson R, LoPresti E, Schreckenghost D. An assistive-technology intervention for verbose speech after traumatic brain injury. Journal of Head Trauma Rehabilitation 2004;19:366-377.

15. Smith MM, Connolly I. Roles of aided communication: Perspectives of adults who use AAC. Disability and Rehabilitation: Assistive Technology 2008;3:260-273.

16. Beukelman DR, Fager S, Ball L, Dietz A. AAC for adults with acquired neurological conditions: A review. Augmentative and Alternative Communication 2007;23: 230-242.

17. Lund SK, Light J. Long-term outcomes for individuals who use augmentative and alternative communication: Part III-contributing factors. Augmentative and Alternative Communication 2007;23:323-335.

18. Jacobs B, Drew R, Ogletree BT, Pierce K. Augmentative and Alternative Communication (AAC) for adults with severe aphasia: Where we stand and how we can go further. Disability and Rehabilitation 2004;26:1231-1240.

19. Kirsch NL, Shenton M, Spirl E, Rowan J, Simpson R, Schreckenghost D, LoPresti EF. Web-based assistive technology interventions for cognitive impairments after traumatic brain injury: A selective review and two case studies. Rehabilitation Psychology 2004;49:200-212.

20. Sohlberg MM, Fickas S, Hung PF, Fortier A. A comparison of four prompt modes for route finding for community travellers with severe cognitive impairments. Brain Injury 2007;21:531-538.

21. Chang YJ, Peng SM, Wang TY, Chen SF, Chen YR, Chen HC. Autonomous indoor wayfinding for individuals with cognitive impairments. Journal of Neuroengineering and Rehabilitation 2010;7:45.

22. Hart T, O’Neil-Pirozzi T, Morita C. Clinician expectations for portable electronic devices as cognitive-behavioural orthoses in traumatic brain injury rehabilitation. Brain Injury 2003;17:401-411.

23. O’Neil-Pirozzi TM, Kendrick H, Goldstein R, Glenn M. Clinician influences on use of portable electronic memory devices in traumatic brain injury rehabilitation. Brain Injury 2004;18:179-189.

24. Hart T, Buchhofer R, Vaccaro M. Portable electronic devices as memory and organizational aids after traumatic brain injury: A consumer survey study. Journal of Head Trauma Rehabilitation 2004;19:351-365.

25. Grol R. Personal paper. Beliefs and evidence in changing clinical practice. British Medical Journal 1997;315:418-421.

26. De Bie SE. Standaardvragen 1987: Voorstellen voor uniformering van vraagstellingen naar achtergrondkenmerken en interviews. Leiden: Stuurgroep Dataverzameling; 1987. VOI. 87.

27. Rogers EM. Diffusion of innovations. 5th ed. New York: Free Press; 2003.

28. de Joode E, van Heugten C, Verhey F, van Boxtel M. Efficacy and usability of assistive technology for patients with cognitive deficits: A systematic review. Clinical Rehabilitation 2010;24:701-714.

\section{Appendix: Compound scores}

'Attitude towards the use of assistive technology'

The compound score consisted of six out of eight statements:

(1) AT should be standard care in rehabilitation treatment;

(2) AT is part of modern life and should therefore also be included in rehabilitation treatment;

(3) AT improves the independence of patients;

(4) AT offers much more options than penand-paper cognitive aids;

(5) PDAs can be used successfully in cognitive rehabilitation; and

(6) I am confident that I am able to help the patient to work with a PDA.

Excluded statements were:

(1) Technical knowledge is essential for proper use of a PDA; and

(2) It takes too long for patients to learn to use a PDA. 